3) Murtagh, F. and Kirkpatrick, J.A.: Diagnostic approach to the infant with an enlarging head. JAMA., 172:538-541, 1960.

4) Nulsen, F.E. and Spitz, E.B.: Treatment of hydrocephalus by direct shunt from ventricle to jugular vein. Surgical Forum. Amer. Coll. Sorg., 3:399-403, 1952.

5) Payr, E.: Drainage der Hirnventrikel mittelst frei transplantierter Blutgefässe: Bemerkungen über Hydrocephalus. Arch. klin. Chir., 87:801-885, 1908.

6) Pudenz, R.H., Russell, F. E., Hurd, A.H. and Shelden, C.H.: Ventriculoauriculostomy: A technique for shunting cerebrospinal fluid into the right auricle. Case report. J. Neurosung., 14:171-179, 1957.

7) Pudenz, R.H.: Experimental and clinical observations on the shunting of cerebrospinal fluid into the circulatory system. Clinical Neurosung., Vol. 5, 1958.

8) Pudenz, R. H., Russell, F.E. and Agnew, W.F.: Experimental hydrocephalus, a historical summary. Bull. of the Los Angeles Neurol. Society. Vol. 25, No. 3. September, 1960.

9) Pudenz, R.H.: Surgical treatment of infantile hydrocephalus. Disorders of the developing nervous system. Proc. of Houston Neurol. Society, Charles C. Thomas, Pub. 1961.

10) Robertson, J.R., Schick, R.W., Morgan, F. and Matson, D.D.: Accurate placement of ventriculo-atrial shunt for hydrocephalus under electrocardiographic control. J. Neurosurg., 18:255-257, 1961.

11) Wcstropp, C.K. and Barber, C.R.: Growth of the skull in young children. -I. Standards of head circumference. J. Neurol., Neurosurg and Psychiat., 19:52-54, 1956

Discussion to Dr. Pudenz' Speech (1)

\title{
Hydrocephalus and its various subtypes
}

\author{
Keiji Sano \\ Dept. of Neurosurgery, Faculty of Med. Univ. of Tokyo.
}

\section{Mr. President! Colleagues and Guests!}

I am greatly impressed with Dr. Pudenz' excellent presentation of his own invention, the ventriculoatrial shunt. Since I am asked by President Mitsuno to discuss his paper, I would like to add our small experiences of the procedure and would then refer to the subtypes of infantile hydrocephalus, namely, hydroencephalodysplasia and Chiari-Arnald syndrome.

Hydrocephalus is a state that the cerebrospinal fluid abnormally accumulates in the cranium to cause intracranial hypertension. There must be many types and many causes. Except those due to tumors, we have experienced 133 cases of hydrocephalus for the last ten years, as shown in Table 1. The veniriculoatrial shunt has been performed on 36 cases, as seen in Table 2. Good results are obtained in $70 \%$ of the cases in the follow-up. In spite of the complications listed in the slide, I believe that 
Table 1. Type of Hydrocephalus

133 cases

1 non-communicating hydrocephalus. . 55 stenosis of Foramen Monroi........ 1 aqueductal stenosis .............. 5

Dandy-Walker syndrome .........12

Dandy-Walker syndrome with cervical meningocele ........... 1 secondary basilar impression (chondrodystrophia (foetalis) ....(4) site of lesion unknown ..........24 post-meningitic ............... 6

2 communicating hydrocephalus ......18

3 dysgenetic hydrocephalus

(hydroencephalodysplasia) ...... 9

4 type unknown $\ldots \ldots \ldots \ldots \ldots \ldots 9$

5 Chiari-Arnold syndrome..........42

with spina bifida (S-type) ........15

without spina bifida (C-type).......14

with basilar impression (B-type) ....13
Table 2. Ventriculo-Atriostomy for Intantile Hydrocephalus

$\begin{array}{lr}\text { I No. of operations } & 36 \text { cases } \\ \text { Age distribution } & 2 \mathrm{~m}-7 \mathrm{y} \\ \text { Type of hydrocephalus } & \\ \text { non-communicating } & 19 \text { cases } \\ \text { communicating } & 9 \\ \text { dysgenetic } & 5 \\ \text { Chiari-Arnold } & 3\end{array}$

II Results of operation

(A) Follow up studies (the longest follow up: 5 years) improved 30 cases at present in good condition $25 \quad 70 \%$ not improved 6

(B) Postoperative complicatiaus in earlier stage acute cardiac arrest acute pulmonary edema obstruction of the tube local wound infection

in later stage infection (meningitis, sepsis) 3 obstruction of the tube 5 (venous thrombosis) distracted shunts due to growth 3

(C) Revision

this shunting operation is the most effective procedure for the treatment of hydrocephalus at present and should be performed as early as possible before intracranial hypertension does cause severe cerebral damages.

The most important point of this procedure is to place the distal end of the cardiac tube precisely into the right atrium. As shown in Figure 1 and Figure 2, we are cheking the position of the tip by the following three guides:

1) measurement of the distance between the inserting point and the right atrium.

2) changes of speed of dripping infusion of physiological saline through the cardiac tube, as the tube gradually proceeds in the venous system. (When the distal end of the tube is in the right atrium, the dripping speed is maximum, usually more than 1.5 times as the initial speed.)

3) Changes of ECG. (When the end of the tube goes into the cardiac ventricle, ventricular extrasytole appears in the electrocardiographic tracings. If the extrasystole reverts to a normal rhythm, when the tube is withdrawn a little, the tip is in the right atrium. We are using ordinary ECG techniques as Mark and Sweet ${ }^{1 \text { ' }}$ did. The intracardiac lead as advocated by Robertson and others ${ }^{2}$ has not 


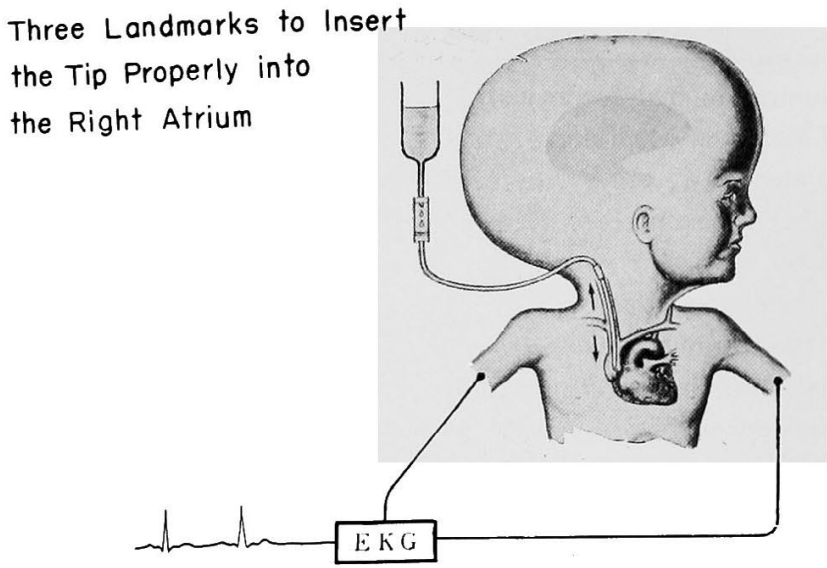

Fig. 1. Three landmarks to insert the tip properly into the right atrium

1) Measurement of the length between the orifice (the facial vein) and the upper margin of the sternal end of the clavicle and that between the latter and the r. atrium (on X-ray films)

2) Changes of speed of dripping infusion of physiological saline solution through the tube, as the tube gradually proceeds in the venous system

3) Changes of ECG (ventricular extrasystole)

T.N. 10

Ventriculoatriostomy ECG
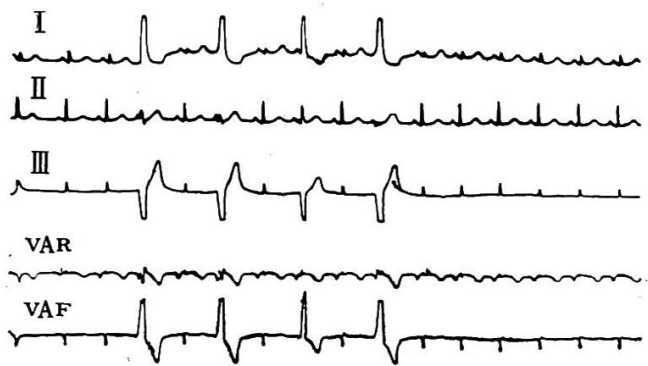

Fig. 2. Three landmarks to insert the tip properly into the $\mathrm{r}$. atrium

been successful in our hands because of many artifacts.)

In 5 out of 9 cases of hydroencehalodysplasia or dysgenetic hydrocephaly, the subarachnoid-atrial shunt was performed, with good results in 4 cases. The slide (omitted) shows a case with absence of the frontal, temporal and Rolandic regions on the right side accompanied by accumulation of the cerebrospinal fluid in the subarachnoid space.

We prefer the name "Chiari-Arnold syndrome" to Arnold-Chiari malformation, in honor of Hans Chiari who first described the sydrome in $1891^{3) 4}$, 3 years before the report of Julius Arnold ${ }^{5)}$. As shown in Table 3, 
Table 3. Chiari-Arnold Syndrome (Arnold-Chiari Malformation)

Chiari's Classification (1891, 1895)

1. herniation of the interior portion of the cerebellum with hydrocephalus with meningocele (Age $3 \frac{1}{2} \mathrm{M}-68 \mathrm{Y}$ )

2.

herniation of the inferior portion of the cerebellum, the brain stem and the 4th ventricle

with hydrocephalus and spina bifida (Age $0-6 \mathrm{M}$ )

3. herniation of the cerebellum into the cervical meningocele (Age 5 M)

Table 4. Chiari-Arnold Syndrome S-Type (with Spina Bifida) 15 cases

Clinical Symptoms

\begin{tabular}{lc}
\hline Enlarged head circumference & 15 cases \\
Mental retardation & 3 \\
Convulsion & 3 \\
Visual Disturbance & 2 \\
Choked disc & 2 \\
Vertical nystagmus & 1 \\
Spastic paresis of upper extremities & 1 \\
Gait disturbance & 5 \\
Spastic paresis of lower extremities & 2 \\
Flaccid paresis of lowe extremities & 6 \\
Deformity of feet & 3 \\
Incontinentia urinae et albi & 8 \\
Sensory disturbance of lower & \\
extremitis & 4
\end{tabular}

our Classification (1964)

1) C-type

14 cases ptosis of the inferior portion of the cerebellum without spina bifida

(Age $17 \mathrm{Y}-40 \mathrm{Y}$ )

\section{2) S-type}

with spina bifida

(Age $0-4 \mathrm{Y}$ )

3) B-type

with basilar impression

(Age $12 \mathrm{Y}-39 \mathrm{Y}$ )

Table 5. Chiari-Arnold Syndrome S-Type (with spina bifida)

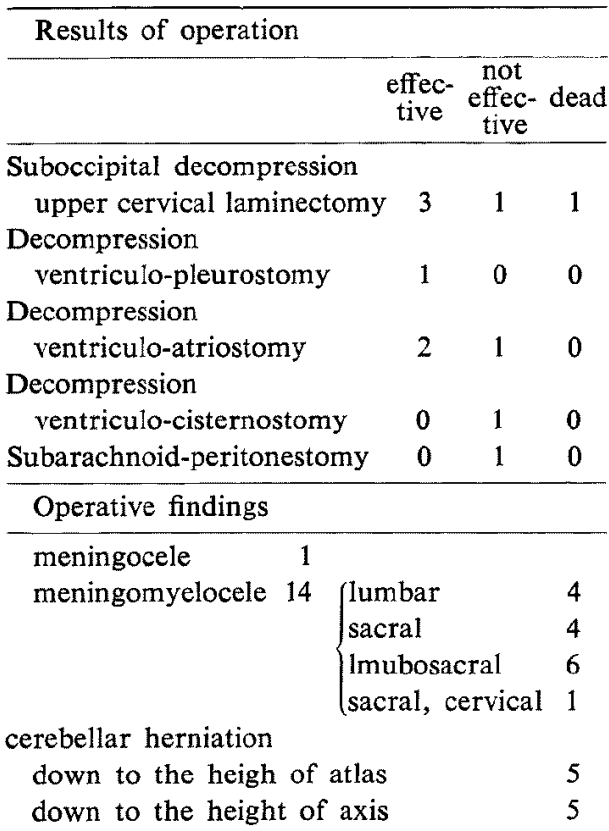

we divide this syndrome into three types: the C-type with ptosis of the inferior portion of the cerebellum and no spina bifida (14 cases), the S-type with spina bifida (15 cases) and the B-type with basilar impression (13 cases).

The onset of symptoms in the B-and C-types is mostly after 10 years. whereas the S-type exhibits hydrocephalus before 26 months. Therefore, as 


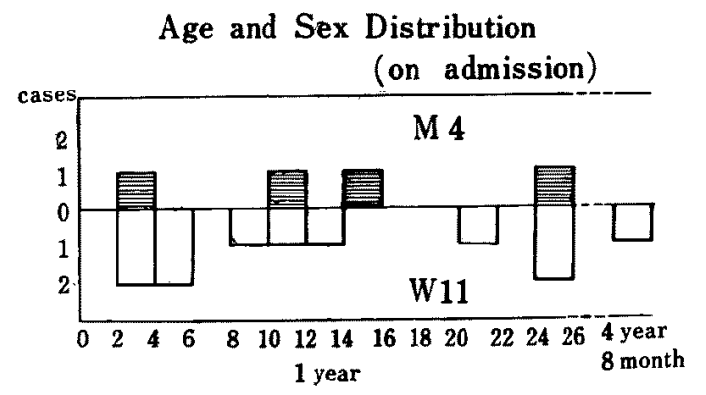

Onset of Hydrocephalus

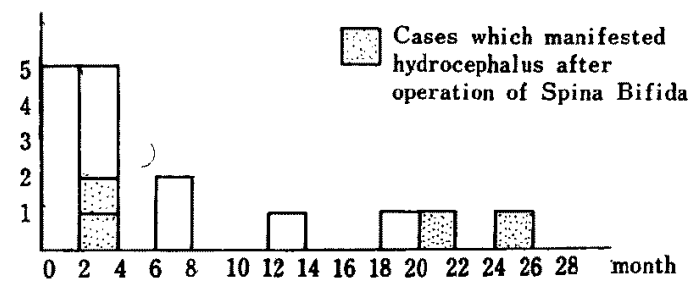

Fig. 3. Chiari-Arnold Syndrome, S-Type (with Spina Bifida)

infantile hydrocephalus, only the S-type becomes a subject of discussion. The age and sex distribution and the onset of hydrocephalus in the S-type is illustrated in Figure 3.

Clinical manifestations of the S-type are tabulated in Table 4. Table 5 shows the results of operation and the operative findings. Suboccipital decompression is often not enough and shunting procedures are necessary. Good results are obtained in $60 \%$ in the follow-up. Early discovery and early treatment will improve the results.

In conclusion, I believe with Dr. Pudenz, the ventriculoatrial shunt is the most effective procedure available at present for the treatment of hydrocephalus, not only of its ordinary types, but of some its subtypes.

Thank you for your attantion.

\section{Reference}

1) Mark, V.H. \& Sweet, W.H.: Ventriculoatriostomy; A technical note: The accurate placement of the distal end of the shunt into the right atrium without $x$-ray control. Neurochirurgia, 3: 115-120, 1960.

2) Robertson, J.T., Shick, R.W., Morgan, F. \& Matson, D.D.: Accurate placement of the ventriculo-atrial shunt for hydrocephalus under electro-cardiographic control. J. Neurosurg., 18: 255-257, 1961 .

3) Chiari, H.: Über Veränderungen des Kleinhirms infolge von Hydrocephalie des Grosshirns. Deutsch. med. Wschr., 17: 1172-1175, 1891.

4) Chiari, H.: Über Veränderungen des Kleinhirns, des Pons und der Medulla oblongata infolge von kongenitaler Hydrocephalie des Grosshirns. Denkschr. Akad. Wiss. Wien, 
$63: 71-116,1895$.

5) Arnold, J.: Myelocyste, Transposition von Gewebskeimen und Sympodie. Beitr. z. pathol. Anat. u.z. allg. Patol., 16: 1-28, 1894.

Discussion to Dr. Pudenz' Speech (2)

\section{Komei UEKI}

Dept. of Neurosurgery, Brain Research Institute, Niigata Univ. School of Medicine

We have been most fortunate to have an occasion to hear Dr. Pudenz discusses his work. His results are clear-cut and his analysis of the clinical data is excellent. I think all can agree, that for the present time at least, his procedure is the one of choice from the many procedures availabe for the treatment of congenital hydrocephalus.

We too have had experience in his method with good results even though the instruments used by us are modified in some respects to his instruments. For example, in our series there were two slits in the cardiac tube and no diaphragm valve for the flushing device. It will be noted that in tables 1 and 2, the clinical results obtained with this method are obviously better than those obtained by previously used methods. In respect to the newer method however, it must unfortunately be pointed out, that in some instances we experienced an obstruction to the cardiac end of the tube. Out of twenty four cases, five had to be subjected to repeated operation two or three times.

On the other hand, in previous series, a thrombosis of the major arteries or veins was a common occurence; in the newer method such a complication was not encountered in our experience. I wonder if this finding, together with the experience of other workers in the field of general surgery, does not indicate that thrombosis occures less frequently in the Japanese. In

Table 1. Results of ventriculoatriostomy (1.5 Months to 3 Years)

\begin{tabular}{lr}
\hline 1) Alive: \\
Hydrocephalus arrested & 16 \\
& Still progressive \\
2) Dead & 2 \\
3) Unknown & 5 \\
\hline Total & 1 \\
\hline
\end{tabular}

Table 2. Surgical results of hydrocephalus under two years of age

\begin{tabular}{|c|c|c|c|c|c|}
\hline & Alive & $\begin{array}{l}\text { Dead } \\
\text { within } \\
\text { one } \\
\text { month }\end{array}$ & $\begin{array}{c}\text { Dead } \\
\text { over } \\
\text { one } \\
\text { month }\end{array}$ & $\begin{array}{c}\text { Un- } \\
\text { known }\end{array}$ & Total \\
\hline V. mastoidost. & & 2 & 2 & & 3 \\
\hline Torkildsen's proc. & & 1 & & & 1 \\
\hline V. peritoneost. & & 1 & & & 1 \\
\hline V. salpingost. & & & & 1 & 1 \\
\hline Plexect. & & 1 & & & 1 \\
\hline V. atriost. & 11 & 3 & 2 & 1 & 17 \\
\hline Total & & & & & 24 \\
\hline
\end{tabular}

